\title{
Copias, postproducciones y otras estéticas del guardar-como
}

\author{
DOMINGO HERNÁNDEZ SÁNCHEZ \\ Universidad de Salamanca
}

\begin{abstract}
A MEDIADOS DEL SIGLO XIX, Gustave Flaubert ideó un proyecto apasionante para la segunda parte de su Bouvard y Pécuchet. Se trataba de un dispositivo contra la estupidez humana cuyo funcionamiento exigía la articulación de dos elementos, una recopilación de citas y frases que Flaubert consideraba ridículas, tomadas de las fuentes más diversas y sobre todo tipo de asuntos, y una especie de diccionario de tópicos que, según escribe a Louise Colet, compilase «por orden alfabético, todo lo que hay que decir en sociedad para ser un hombre decente y amable sobre todos los temas posibles» ${ }^{1}$. A fin de llevar a cabo tales objetivos, había venido recogiendo durante años un amplísimo volumen de textos, procedentes de innumerables lecturas y búsquedas, que constituiría el material al que los dos oficinistas más famosos de la historia de la literatura habrían de dedicar todos sus esfuerzos, una vez tomada la decisión de «volver a su trabajo de copistas ${ }^{2}$. Ése era el plan que Flaubert había configurado como segunda parte de Bouvard y Pecuchet y que, por desgracia, no pasó de la categoría de proyecto. Disponemos, sin embargo, de parte de los materiales recogidos, que constituyen lo que se conoce como Estupidario [Le Sottisier], la colección de citas, y el Diccionario de prejuicios [Dictionnaire des idées reçes], esa recopilación de tópicos y opiniones socialmente aceptadas que, en el fondo, definen al estúpido ideal. El objetivo didáctico de Flaubert con el diccionario era evidente, pues se trataba de que los lectores, al contemplarse reflejados en alguno de los prejuicios, abandonasen ese punto de vista.

Dos copistas, por tanto, tras fracasar en sus múltiples proyectos de sabiduría, deciden volver a su antiguo trabajo, copiar, y su creador los sitúa ante un cúmulo de materiales representativos de la estupidez más común. Copiar
\end{abstract}

1 Tomo la cita del prólogo de Agustín Izquierdo a su edición de: G. Flaubert, Estupidario. Diccionario de prejuicios, tr. A. Izquierdo, Madrid: Valdemar, 1995, p. 11.

2 G. Flaubert, Bouvard y Pécuchet, tr. G. Palacios, Madrid: Cátedra, 1999, p. 322. 
estupideces e inventariar tópicos y prejuicios del siglo XIX, ideas recibidas... No es de extrañar que a la vista de tales tareas, llame poderosísimamente la atención uno de los tópicos recogidos en tan curioso diccionario, el que define la entrada OrIGINAL:

ORIGINAL. Reírse de lo original revela una gran superioridad mental. Reírse de todo lo que es original, odiarlo, escarnecerlo y exterminarlo si se puede. Maneras de pasar por original. ${ }^{3}$

Si quisiésemos hoy redactar un nuevo Diccionario de prejuicios, proyecto que, debido a la actual aglomeración de tópicos, casi habría de considerarse como necesario, para esta entrada podríamos dejar tal cual las palabras de Flaubert. Es cierto que un Diccionario de prejuicios escrito a comienzos del siglo XXI sería inagotable, pero tal hecho no modifica la sorpresa ante esa entrada, sobre todo leída desde nuestra situación actual. En efecto, como nos han enseñado todo tipo de modelos postmodernos, postestructuralistas y neovanguardistas, reírse de lo original revela una gran superioridad mental, del mismo modo que, si nos guiamos por las palabras de Flaubert, lo hacía en el siglo XIX. Es cierto que los contextos se han modificado, como no podía ser menos, pero el hecho es que el cúmulo de simulaciones, apropiaciones y postproducciones si en algo coinciden es en la negación de «esa enfermedad romántica, la originalidad», como la define William Gaddis en Los reconocimientos ${ }^{4}$, una novela fundamental para el tema que nos ocupa y a la que volveré más adelante.

Efectivamente, nuestra cultura actual es una cultura de la copia, aludiendo al título del ensayo de Hillel Schwartz ${ }^{5}$, y no sólo de la copia: también lo es de la reproducción, la postproducción y la serialización, modelos todos ellos de una dialéctica de repeticiones y duplicidades que define nuestro imaginario artístico y cultural situándolo ante una extraña exuberancia de la imitación. De hecho, casi podríamos partir de esa irónica definición que hace Jonathan Lethem en «Con K de kopia»: «Por imitación entiéndase: falsificación, copia, ventriloquia, suplantación del padre, suplantación del gentil, suplantación del genio, usurpación del guionista» ${ }^{6}$. Porque, y aunque no sea necesario mencionarlo, más que nada por evidente, no ha de olvidarse en ningún momento que en el ámbito artístico contemporáneo, copia no significa lo mismo que en otros

3 G. Flaubert, Estupidario. Diccionario de prejuicios, op. cit., p. 212.

4 W. Gaddis, Los reconocimientos, tr. J. A. Santos, Madrid: Alfaguara, 1987, p. 109.

5 H. Schwartz, La cultura de la copia. Parecidos sorprendentes, facsímiles insólitos, tr. M. Talens, Madrid: Cátedra (Frónesis), 1998.

6 J. Lethem, «Con K de kopia», tr. C. Rodríguez Juiz, en: D. Eggers (ed.), Lo mejor de McSweeney's, vol. II, Barcelona: DeBolsillo, 2007, p. 259. 
ámbitos culturales o sociales: aquí las copias y las simulaciones son los buenos, y la autenticidad, la originalidad y la singularidad los malos. Quizá nadie como John Banville lo haya mostrado de un modo más explícito: «lo pintoresco me repugna ${ }^{7}$, pone en boca de ese apasionante impostor que es Axel Bander, no por casualidad filósofo y perfecto conocedor de Nietzsche. Aunque, todo sea dicho, parece evidente que Axel Bander no ha leído las investigaciones de Rosalind Krauss sobre el pintoresquismo en «La originalidad de la vanguardia», donde demuestra de un modo lo suficientemente riguroso que «la preexistencia y la repetición de las pinturas es condición necesaria de la singularidad de lo pintoresco» ${ }^{8}$.

Pero volvamos a los tópicos, los más recurrentes, es decir, los de los ambiguos años ochenta del siglo XX. Tópicos duros los de esos años: nuestra realidad no es real sino hiperreal, con lo que los simulacros sin original y los signos sin referente pasan a convertirse en los protagonistas de los debates y en los dueños del lenguaje. Los artistas se adecúan a ello -o, si se muestran reticentes, se les adecúa-mediante todo tipo de estrategias simulacionistas y apropiacionistas, mientras que la crítica, feliz, puede utilizar hasta la extenuación sus herramientas postestructuralistas. Son buenos años para el «discurso de la copia», años de postmodernidad en los cuales todo el mundo parecía intentar contestar a la pregunta de Rosalind Krauss: «¿Qué ocurriría si no se reprimiese el concepto de copia? $\gg^{9}$, pues era evidente que así lo habría hecho la historia del arte, especialmente desde el romanticismo. Para ello, el discurso de la crítica convirtió en elementos recurrentes a Barthes, Derrida y, por supuesto, Baudrillard. Y a Walter Benjamin, claro...

Pobre Benjamin, con su maleta de originales a cuestas, y no era para menos. Debería estar prohibido leer «La obra de arte en la época de su reproductibilidad técnica» sin tener al lado la correspondencia con Gershom Scholem. Recuérdese, y son sólo algunos ejemplos sobre el amigo Ernst Bloch: Benjamin a Scholem, 20 de mayo de 1935 -la primera edición del texto de Benjamin es de 1936-, «si el libro de Bloch cayera en tus manos, te harás fácilmente una idea de en qué medida han tenido éxito sus plagios de mi obra»; Benjamin a Scholem, 24 de octubre de 1935, «estas reflexiones cimentan la Historia del arte del siglo XIX en la comprensión de su situación actual, tal como nosotros la experimentamos. Las mantengo muy en secreto, ya que son incomparablemente más suscepti-

7 J. Banville, Imposturas, tr. D. Alou, Barcelona: Anagrama, 2005, p. 41.

8 R. Krauss, La originalidad de la vanguardia y otros mitos modernos, tr. A. Gómez, Madrid: Alianza, 1996, p. 179. Sobre la actualidad del pintoresquismo, me permito remitir a mi «Pintoresquismo, fotogenia, escenografía y otras estéticas de la sobreexposición», Pliegos de Yuste, 5-6 (2007), pp. 115-125.

9 Ibid., p. 181. 
bles de ser robadas que la mayoría de mis ideas. Su título provisional es "Das Kunstwerk im Zeitalter seiner technischen Reproduzierbarkeit"»; Benjamin a Scholem, 9 de agosto de 1935, «veo a Ernst Bloch, al que he aclarado, con un gran esfuerzo, mi opinión sobre su último libro. No le hablé del mío y sabrás por qué cuando veas en el suyo el capítulo "Hieroglyphen des neunzehnten Jahrhunderts"», a lo que Scholem contesta el 25 del mismo mes, y quizá sea la referencia más sangrante: «Así que, ahora nos encontramos cada uno ante un asunto importante, pues yo también he empezado ya, con no poco esfuerzo, a trazar letra tras letra sobre el papel, para lo que, por precaución ante Ernst Bloch, me sirvo de la lengua de nuestros padres. Bastante me robará después. [...] Por cierto y a propósito de tu irritación por causa de Bloch: he vuelto a leer el capítulo que indicas y sólo puedo decirte que me das pena. En verdad no favorece tu situación el que tengas que aguantar esta camaradería de ladrones realmente 'conmovedora' y, en realidad, me parece demasiada bondad por tu parte» ${ }^{10}$. Y eso que, leo a Benjamin, «el aura está ligada a su aquí y ahora. Del aura no hay copia» ${ }^{11}$. Para desgracia de Benjamin, una más, sus textos no debían tener demasiada.

Ahora bien, ya no estamos en los años ochenta del pasado siglo y, por tanto, hemos dejado de ser postmodernos. Baudrillard cansa, la simulación aburre y el postestructuralismo ya no es el lenguaje oficial. Los simulacros y la nietzscheana inversión del platonismo eran muy divertidos, pero actualmente somos tan conscientes de ellos que hasta les hemos tomado cariño. No, ya no somos postmodernos, para lo bueno y para lo malo; por supuesto, no sabemos lo que somos ahora, pero desde luego postmodernos no. Entre los términos oficiales ya no se encuentran apropiación o simulación, sino, por ejemplo, el que ha puesto de moda Nicolas Bourriaud, postproducción. Todo ello exige una nueva lectura del discurso de la copia $-\mathrm{y}$ del de la originalidad-, sobre todo porque tanto la postproducción como la estética relacional de Bourriaud ${ }^{12}$ requieren ampliar el contexto, es decir, conducir el discurso artístico a un marco mucho más amplio, donde el arte solamente sea una faceta más de determinadas actividades culturales y sociales.

Las tesis de Bourriaud, utilizando sus propios términos, podrían concretarse en la siguiente cita, una cita extensa, pero que ha de servirnos como resumen general de sus teorías:

10 W. Benjamin; G. Scholem, Correspondencia, 1933-1940, tr. R. Lupiani, rev. B. Llovet, Madrid: Taurus, 1987, p. 179, p. 191, p. 184 y pp. 185-186, respectivamente.

11 W. Benjamin, «La obra de arte en la época de su reproductibilidad técnica», en W. Benjamin, Discursos interrumpidos, I. Filosofía del arte y de la historia, tr. J. Aguirre, Madrid: Taurus, 1992 (4. ${ }^{\text {a }}$ reimp.), p. 36.

$12 C f$. N. Bourriaud, Estética relacional, tr. C. Beceyro y S. Delgado, Buenos Aires: Adriana Hidalgo editora, 2006. 
Todas estas prácticas artísticas, aunque formalmente muy heterogéneas, tienen en común el hecho de recurrir a formas ya producidas. Atestiguan una voluntad de inscribir la obra de arte en el interior de una red de signos y de significaciones, en lugar de considerarla como una forma autónoma u original. Ya no se trata de hacer tabla rasa o crear a partir de un material virgen, sino de hallar un modo de inserción en los innumerables flujos de la producción. [...] La pregunta artística ya no es: «¿qué es lo nuevo que se puede hacer?», sino más bien: «¿qué se puede hacer con?». Vale decir: ¿cómo producir la singularidad, cómo elaborar el sentido a partir de esa masa caótica de objetos, nombres propios y referencias que constituye nuestro ámbito cotidiano? De modo que los artistas actuales programan formas antes que componerlas; más que transfigurar un elemento en bruto (la tela blanca, la arcilla, etc.), utilizan lo dado. Moviéndose en un universo de productos en venta, de formas preexistentes, de señales ya emitidas, edificios ya construidos, itinerarios marcados por sus antecesores, ya no consideran el campo artístico (aunque podríamos agregar la televisión, el cine o la literatura) como un museo que contiene obras que sería preciso citar o «superar», tal como lo pretendía la ideología modernista de lo nuevo, sino como otros tantos negocios repletos de herramientas que se pueden utilizar, stocks de datos para manipular, volver a representar y a poner en escena. [...] El prefijo «post» no indica en este caso ninguna negación ni superación, sino que designa una zona de actividades, una actitud. Las operaciones de las que se trata no consisten en producir imágenes de imágenes, lo cual sería una postura manierista, ni en lamentarse por el hecho de que todo «ya se habría hecho», sino en inventar protocolos de uso para los modos de representación y las estructuras formales existentes. Se trata de apoderarse de todos los códigos de la cultura, de todas las formalizaciones de la vida cotidiana, de todas las obras del patrimonio mundial, y hacerlos funcionar. Aprender a servirse de las formas [...] es ante todo saber apropiárselas y habitarlas ${ }^{13}$.

Los artistas en los que está pensando Bourriaud son lo suficientemente conocidos, Rirkrit Tiravanija, Thomas Hirschhorn, Mike Kelley, Liam Gillick, Pierre Huyghe, Philippe Parreno, etc. Todos ellos, siguiendo la lectura de Bourriaud, continúan un trayecto histórico-artístico más o menos estipulado. Así, partiendo de la tradición duchampiana, y una vez asumidos la simulación, el apropiacionismo y la escultura de bienes de consumo, tales prácticas artísticas se situarían junto a las del DJ o el web surfer en su objetivo de inventar «itinerarios a través de la cultura», utilizando a ésta como material artístico $\mathrm{y}$, por tanto, asumiendo la contingencia de sus propias obras, pues también

13 N. Bourriaud, Post producción. La cultura como escenario: modos en que el arte reprograma el mundo contemporáneo, tr. S. Mattoni, Buenos Aires: Adriana Hidalgo editora, 2004, pp. 13-14. 
ellas pasan a convertirse en nuevo material a utilizar: con la terminología de Bourriaud, claramente influida por La invención de lo cotidiano de Michel de Certeau, la obra se convierte en «un generador de actividades» y su contexto «podríamos aventurarnos a llamar[lo] un comunismo formal» ${ }^{14}$. Siendo esto así, resulta evidente que si queremos pensar este modelo debemos entender el ámbito artístico como un elemento situado en un contexto mucho más amplio, que remite a la cultura en general y, por tanto, tales prácticas han de asumir que su análisis no discurra únicamente desde la crítica o teoría artística. Por supuesto, podría hacerse desde una coherencia histórico-artística, incluso con un esquema lo suficientemente fiable: en la teoría, iniciarlo en las investigaciones de Gombrich sobre la ambiguiedad de la mímesis clásica-«sin un medio y sin un esquema que pueden moldearse y modificarse ningún artista podrá imitar la realidad» ${ }^{15}$, continuarlo con las investigaciones de Rosalind E. Krauss sobre el carácter ficticio de la originalidad de la vanguardia, etc.; en la práctica, acudir al collage, al pastiche, al ready-made, a la simulación y apropiación... Sin embargo, hacerlo así volvería a situar el discurso artístico dentro de un marco cerrado del que los artistas de la postproducción pretenden salir: si algo nos ha enseñando Bourriaud es que al analizar este cúmulo de propuestas, ya no hablamos únicamente de arte.

Y, sin embargo, si hacemos esto, si situamos el actual discurso de la copia dentro de un marco que supera ampliamente el artístico, entonces debemos asumir todas sus ambigüiedades. Por supuesto, no hablo de artistas concretos o de unas piezas determinadas, que exigirían un análisis particularizado, sino del modelo teórico general. En ese modelo, desde el cual somos completamente libres para acudir a otros espacios de discusión y a otros tiempos -ello explica mi inicio con Flaubert- e incluso para servirnos, aunque de otro modo, de los mismos referentes que se han venido utilizando, surge de un modo muy claro la sospecha de que quizá todo esto no sea más que un discurso nostálgico que esconde innumerables paradojas. Quizá todo oculte una nostalgia de postmodernidad; quizá, incluso, y sería más problemático, tal nostalgia aluda, utilizando las palabras de Flaubert, simplemente a nuevas maneras de pasar por original. Expresado de un modo más claro -y ésta es la idea de la que parto, que se ramifica en dos direcciones-, en primer lugar los actuales discursos de la copia y del doble, al permitir su extensión temporal a otros marcos, muestran que sus estrategias, instrumentos y modelos ya los conocemos, ya los hemos utilizado y, por tanto, quizá nos encontremos ante una repetición de metodologías que no sabemos muy bien hacia dónde nos llevará.

14 Ibid., p. 14, p. 17 y p. 17, respectivamente.

15 E. H. Gombrich, Arte e ilusión. Estudio sobre la psicología de la representación pictórica, tr. G. Ferrater, Madrid: Debate, 1998, p. 126. 
Pero, además, y en segundo lugar, si permutamos el tiempo por el espacio y, por tanto, no pensamos únicamente en historias, sino en utilizaciones contemporáneas del discurso de la copia y la repetición en contextos ajenos al puramente artístico, entonces nos encontramos con una efervescencia serial -muy habitual en el cine y la televisión- que, como han demostrado Balló y Pérez en ese entretenidísimo ensayo que es Yo ya he estado aquí. Ficciones de repetición, «configura un paisaje de cotidianeidad que se refleja a la vez en la costumbre privada y en los rituales colectivos, a partir de un reencuentro periódico que fortalece y preserva la noción de identidad» ${ }^{16}$. O, de otro modo, en ámbitos ajenos al artístico y que remiten a la cultura contemporánea entendida del modo más general posible, las estrategias de copia y repetición no son más que modelos para preservar ciertas identidad y originalidad con claros objetivos de mercado. Es aquella idea que ya había expresado Lyotard en Lo inhumano: «el secreto de un éxito artístico, lo mismo que el de un éxito comercial, radica en una dosificación entre lo sorprendente y lo "bien conocido", entre la información y el código. Tal es la innovación en las artes: se retoman fórmulas confirmadas por éxitos precedentes, se las desequilibra por medio de combinaciones con otras fórmulas en principio incompatibles y de amalgamas de citas, ornamentaciones, pastiches. [...] De tal modo, se cree expresar el espíritu del tiempo, cuando no se hace sino reflejar el del mercado. La sublimidad ya no está en el arte, sino en la especulación sobre el arte» ${ }^{17}$. El contexto desde el que hablaba Lyotard era otro, pero su sospecha no deja de aparecer cuando ampliamos el actual discurso de la copia más allá de los límites de las prácticas artísticas.

Quizá el mejor modo de expresar lo que quiero decir sea volver a esa novela que aparecía anteriormente, Los reconocimientos. La impresionante novela de Gaddis tiene como protagonista a Wyatt Gwydon, un artista dedicado a la copia de los pintores flamencos, pero no es, ni mucho menos, la enésima aventura de falsificadores y demás tablas de Flandes: la complejísima novela de Gaddis incluye multitud de referentes - Nietzsche, Benjamin...-y, temáticamente, críticas a la originalidad, negaciones de todo tipo de trascendencia, triunfos del signo... es decir, una novela postmoderna en su sentido más clásico, pero, no se olvide, escrita en $1955^{18}$. No está de más insistir en la fecha, 1955, porque es posible

16 J. Balló; X. Pérez, Yo ya he estado aquí. Ficciones de repetición, tr. N. Pujol, Barcelona: Anagrama, 2005, p. 9.

17 J.-F. Lyotard, Lo inhumano. Charlas sobre el tiempo, tr. H. Pons, Buenos Aires: Manantial, 1998, p. 110.

18 Para un acercamiento detallado a la compleja obra de Gaddis, véase, por ejemplo, la guía de lectura elaborada por Steven Moore, A reader's guide to William Gaddis 'The Recognitio$n s^{\prime}$, disponible en http://www.williamgaddis.org/recognitions/trguide.shtml [Fecha de consulta: 15/VII/2007]. 
afirmar que gran parte de los avatares de las prácticas artísticas en los últimos cincuenta años habitualmente han estado precedidos por los literarios, con lo que, si partimos de entender la posibilidad de cierto paralelismo, estos últimos nos pueden ser muy útiles. En el caso de Gaddis, como dice Marc Chénetier, «transcribiendo a la escritura los problemas y también la conciencia del imitador y del falsario, Gaddis explota una intertextualidad prolija, cita del derecho y del revés, modifica sus fuentes y altera sus referencias y sus alusiones» ${ }^{19}$. Pues bien, el bueno de Wyatt Gwydon muestra una idea que considero fundamental para lo que nos ocupa: sus obras propias siempre quedaban sin terminar, no pasaban de bocetos, de dibujos incompletos, y sólo las copias llegaban a concluirse. «Más o menos cada semana solía empezar algo original. Trabajaba en ello durante días, pero lo dejaba antes de trazar ninguna línea definitiva. Sin embargo, seguía haciendo copias a la perfección, con esa perfección que sólo la falsificación puede alcanzar, reproduciendo todo rasgo de insuficiencia, toda tacha en perfección que mostrara el original», escribe Gaddis ${ }^{20}$. Atendiendo a esto, únicamente la copia puede ser perfecta: en un mundo de signos, en un mundo sin originales, sólo la copia adquiere los caracteres del viejo arte y, por tanto, se constituye como elemento por excelencia de las sospechas de nostalgia. Por ello, no puedo evitar recordar a Gaddis y a su Wyatt Gwydon siempre que se alude a la postproducción y a la actual cultura de la copia en el sentido de negación de modelos clásicos.

A todo esto remite el título de este artículo, y aprovecho así para explicarlo. Llamo estética del guardar-como, o cultura del guardar-como, a los actuales modelos de repetición, serialización y postproducción cuando van acompañados de ciertas sospechas y ambigüedades en lo que remite a sus estrategias; sospechas y ambigüedades, entiéndase bien, que únicamente aparecen si ampliamos los marcos, en el espacio y en el tiempo, del discurso de la copia. Como si, en el fondo, y de un modo levemente irónico, todo continuase las directrices procedentes de Windows y entre la creación y la repetición se situase constantemente ese modelo del guardar-como, que nos permite un discurso de la copia sin perder la originalidad y una originalidad sin disuadir los elementos de repetición; como si la leyenda del gemelo desaparecido, ese relato que nos dice que todos somos copias, que nos engendran como gemelos, pero nacemos únicos, hubiese vuelto para mostrar todos los elementos de sospecha, de confusión de identidades y problemas con la duplicidad. Para Hillel Schwartz, y es de él de quien tomo la referencia, «la leyenda del gemelo desaparecido se refiere a una pérdida lamentable y a una vida de compañerismo idéntico y

19 M. Chénetier, Más allá de la sospecha. La nueva ficción americana desde 1960 hasta nuestros días, tr. M. Lozano, Madrid: Visor, 1997, p. 46.

20 W. Gaddis, op. cit., p. 71. 
tranquilizador: gemelos siameses, configurados por modernas nociones de un verdadero ser tan independiente y libremente deseado evoca el terror de un doble antitético e indestructible» ${ }^{21}$. Deseo de ser doble... para manifestar aún más los modelos de singularidad, originalidad e identidad. Discurso repleto de paradojas y sospechas, como la publicidad, el modelo gemelar por excelencia, porque es evidente que «la publicidad es algo absolutamente gemelar: una profesión dedicada a repetir, a hacer que lo viejo parezca nuevo en un mundo que favorece el que todo sea "el doble de largo y el doble de cantidad" y el "compre uno y obtenga otro gratis" y el "doble su placer o doble su dinero". Porque esta generalidad está patrocinada por una fe comercial en que el consumir ha de ser una pasión, tal como debió de serlo en la matriz; en que el consumidor debe estar siempre insatisfecho, como le sucede al que no es gemelo; en que, a través de la hipérbole, un bien de consumo puede dejar atrás a los que son como él para convertirse en una marca» ${ }^{22}$.

Para mostrar esto, para intentar presentar las ambigüedades que recorren actualmente el discurso de la copia, resaltando de entre ellas la sospecha de que quizá todo esto no sea más que una nostalgia de originalidad, cosa que, ahora ya, no sería nada demasiado grave, pero sí modificaría determinadas lecturas, me serviré de una serie de conexiones. La función de tales conexiones consiste en que, primero, me permitan mostrar esa idea de que estamos ante paradigmas completamente conocidos -repetición de metodologías, además de repetición de contenidos, por tanto-, hecho que puede ser problemático, y, segundo, pueda utilizar sus consecuencias como materiales e instrumentos para concretar ciertas tesis finales. Evidentemente, los referentes que utilizaré tendrán que ver con todo tipo copias, falsificaciones y repeticiones, pero remitirán a contextos espaciales y temporales diversos.

Si partimos de considerar el discurso sobre la postproducción de Bourriaud como un elemento fundamental en el nuevo discurso de la copia, interesa de un modo especial entenderlo como referente. A partir de Bourriaud, podrían realizarse tres conexiones, tres desplazamientos particularmente interesantes, que definiré como 1) la generación de acontecimientos, 2) el comunismo formal y 3) la metáfora del bazar. Su dialéctica sería la siguiente:

- La generación de acontecimientos. Para Bourriaud, como mencioné de pasada más arriba, «la obra de arte contemporánea no se ubicaría como la conclusión del "proceso creativo" (un "producto finito" para contemplar), sino como un sitio de orientación, un portal, un generador de actividades» ${ }^{23}$.

21 H. Schwartz, op. cit., p. 54.

22 Ibid., p. 36.

23 N. Bourriaud, Post producción, op. cit., p. 16. 
Generador de actividades porque las postproducciones navegan en las redes de signos y significados, pasando a representar nuevos sentidos que permiten su asimilación posterior mediante "potenciales reutilizaciones", con lo que «el arte vendría a contradecir la cultura "pasiva" que opone las mercancías y sus consumidores, haciendo funcionar las formas dentro de las cuales se desarrollan nuestra existencia cotidiana y los objetos culturales que se ofrecen para nuestra apreciación» ${ }^{24}$. Pero tal idea, la de la postproducción, o, por qué no decirlo claramente, la duplicación como generación de acontecimientos es algo clásico en todo discurso de copias y falsificaciones. Recuérdese el que es, seguramente, el más famoso discurso de la falsificación, aquel pequeño "poema en prosa" de Baudelaire, «La moneda falsa»: tras entregarle la moneda falsa al mendigo, hecho éticamente inclasificable, «una conducta tal, por parte de mi amigo, no era excusable sino por el derecho de producir un acontecimiento en la vida de aquel pobre diablo, quizá, incluso, de conocer las distintas consecuencias, funestas o de otro tipo, que pudiera engendrar una moneda falsa en la mano de un mendigo» ${ }^{25}$. Esto es lo que permite a Derrida, en Dar (el) tiempo, I. La moneda falsa, libro que una y otra vez circula alrededor de la narración de Baudelaire, afirmar que tanto el texto en cuestión, como la moneda falsa en particular son «una máquina de provocar acontecimientos» ${ }^{26}$, acontecimientos no esperados, acontecimientos que pueden ser tanto positivos como negativos, acontecimientos incontrolables. Máquinas de provocar acontecimientos, como, en el fondo, toda obra de arte, como, por supuesto, lo es el ready-made, o como lo es toda práctica artística que se inmiscuye en la dialéctica de copias y originales. Ello es lo que explica, a su vez, la aglomeración actual de novelas sobre falsificaciones, falsarios, impostores y demás representantes de la cultura de la copia: son formas de generar acontecimientos.

Permítaseme únicamente otro ejemplo, que insiste en la relación entre el arte y el dinero. Por supuesto, en la historia del arte contemporáneo hay multitud de artistas que han tematizado el dinero como objeto artístico u objeto a apropiar, habitualmente para plantear el problema del valor y remitiendo a cierto tipo de bussiness art. Picasso, Pollock, Duchamp, Dalí, Warhol, Morris, Kienholz, Haacke, etc. ${ }^{27}$, han tratado de un modo u otro el tema del dinero, y en la crítica, quizá uno de los análisis más interesantes se encuentre en esa conexión que realiza Rosalind Krauss en Los papeles de Picasso entre el lugar de la moneda

24 Ibid., p. 17.

25 Ch. Baudelaire, «La moneda falsa», en Ch. Baudelaire, Pequeños poemas en prosa / Los paraísos artificiales, tr. J. A. Millán, Madrid: Cátedra, 1986, pp. 101-102.

26 J. Derrida, Dar (el) tiempo, I. La moneda falsa, tr. C. de Peretti, Barcelona: Paidós, 1995, p. 97.

27 Como resumen, véase, por ejemplo, L. Weschler, Boggs. La comedia del dinero, tr. P. Giralt, Barcelona: Seix Barral, 2000, pp. 65-75. 
falsa en Los monederos falsos de André Gide y el cambio en los valores de representación, esa «extraña convergencia cronológica entre el surgimiento de la moneda convencional inconvertible, propia de la economía de posguerra, y el nacimiento del signo estético no referencial» ${ }^{28}$. Yo, sin embargo, siento especial cariño por otro artista, Boggs, cuya historia narra Lawrence Weschler en Boggs. La comedia del dinero.

Boggs se define a sí mismo como un artista del dinero, y su interés, por supuesto, se centra en el tema del valor y todas sus apasionantes complicaciones. Es, en el fondo, un artista de segunda fila y no demasiado conocido, que continúa la vieja tradición de determinados modelos conceptuales críticos, aunque con una pequeña diferencia: para él, las transacciones monetarias son el objeto de arte. Lo que a Boggs le gusta hacer es, por ejemplo, invitar a alguien a cenar en un buen restaurante y, al llegar el momento del café y la copa y recibir la nota, una nota de... digamos 87 dólares, extraer de su cartapacio un dibujo en el que ha trabajado varias horas antes de la cena. El dibujo «podría consistir en este caso en una versión virtualmente perfecta del anverso de un billete de cien dólares. Entonces saca del cartapacio un par de plumas de precisión - una de tinta verde y otra negra- y procede a aplicar los últimos toques al dibujo. Esta actividad causa invariablemente una honda impresión. Los comensales de las mesas vecinas alargan el cuello. Los camareros miran boquiabiertos al pasar. El maître d'hôtel se acerca lentamente, mira un rato con fijeza y por fin elogia al joven la excelencia de su arte. "Estupendo -dice Boggs-, me alegra que le guste este dibujo porque me propongo usarlo como pago de nuestra cena" 29 . Por supuesto, en ese momento el maître palidece: sudor frío, dudas, ¿llama a la policía?, ¡dios mío, otro artista loco! Pero Boggs restaura la calma. Vuelve a introducir la mano en su cartapacio, saca de él un billete de cien dólares auténtico, el modelo que ha utilizado para su dibujo, y dice: «"Como es natural, si quiere puede quedarse en su lugar con este billete auténtico de cien dólares". El color empieza a volver al rostro del maître. "Pero, como puede ver-continúa Boggs-, soy un artista y he dibujado esto, me ha costado muchas horas hacerlo y ciertamente vale algo. Le asigno un precio arbitrario que por casualidad coincide con su valor real: cien dólares. Esto significa que si decide aceptarlo como pago total de nuestra cena, deberá darme trece dólares de cambio. Así pues, tendrá que decidir si cree que esta obra de arte vale más o menos que este billete auténtico de cien dólares. Depende enteramente de usted”. Boggs sonríe, y el maître palidece otra vez, porque ahora está sufriendo un vértigo grave: la caída libre de los precios y los valores» ${ }^{30}$.

28 R. Krauss, Los papeles de Picasso, tr. M. Reilly, Barcelona: Gedisa, 1999, p. 21.

29 L. Weschler, op. cit., pp. 21-22.

30 Ibid., p. 22. 
Boggs ha repetido esta estrategia en multitud de casos y contextos, algunas veces causándole graves problemas con la justicia, sobre todo en Inglaterra, cuando en una muestra en Londres irrumpió la policía, incautó las obras y Boggs dio con sus huesos en la cárcel. Boggs, por supuesto, no hace falsificaciones: sus billetes sólo están dibujados en un lado del papel, y el anverso en blanco siempre incluye la firma y la documentación del artista. Al margen de toda la posible tematización de la actuación de Boggs, basta con saber que el modo de exposición -y sólo se exponen aquellos billetes que consigue gastar- siempre incluyen todo el conjunto: el billete, los recibos y demás datos del negocio. Insisto, sin entrar demasiado en el análisis de las piezas de Boggs, lo que está claro es que los billetes, las copias, incluso las falsificaciones, si se quiere, han de ser considerados «simplemente como pequeñas partes -los catalizadores, por así decirlo- de su verdadero arte, que en realidad consiste en la serie de transacciones que provocan ${ }^{31}$. Provocar transacciones... modelos de actuación conceptual demasiado habituales, aunque no por ello se le reste importancia a la actuación de Boggs: nunca está de más hacer copias a mano (originales, por tanto) de productos técnicos que, además, como es el caso de los billetes, son prototipos por excelencia de singularidad, pues no hay dos billetes idénticos.

Copias, entonces, las de Boggs, como máquinas de provocar acontecimientos, por decirlo con Derrida, copias como lo era la moneda falsa de Baudelaire y como lo es, según Bourriaud, las piezas de los artistas de la postproducción. Si ése es el único carácter, no parece demasiado original. En Boggs, por supuesto, su estrategia se traduce muy a menudo en ese modelo clásico según el cual la copia o falsificación supera al original, constituyendo a la copia, de nuevo, como el mayor suplemento de originalidad. Y digo que es un modelo clásico porque se trata de algo muy habitual en las dialécticas de falsificación y en los discursos de la copia. En la biografía de Elmyr de Hory que escribió Clifford Irving tenemos un ejemplo típico. Recuérdese que Elmyr es uno de los más grandes falsificadores de la historia del arte, que su biógrafo, Clifford Irving, se hizo famoso por una biografía completamente ficticia de Howard Hughes, y que todos ellos son los personajes de la más importante película sobre el fraude artístico rodada jamás, F for Fake de Orson Welles (1973), emulada ahora, sin demasiado éxito, por The Hoax, de Lasse Hallström (2007). Pues bien, en la biografía de Elmyr escrita por Irving -sin olvidar que se trata de la biografía de un falsificador escrita por alguien que a su vez falsea las biografías- hay un momento, cuando Elmyr ya ha pasado a convertirse en mito, en que el marchante Joseph Faulkner contacta con cierto coleccionista al que ha vendido un Modigliani de Elmyr para pedirle que se lo devuelva y reembolsarle el dinero, a lo que el coleccionista contesta: «jJamás! No me desharía de él por nada. Quiero

31 Ibid., p. 24. 
que venga a Minneápolis y escriba al dorso del dibujo: "Yo, Joseph Faulkner, certifico que ésta es una falsificación original y auténtica pintada por Elmyr de Hory" $\gg{ }^{32}$. Historias típicas donde la falsificación asume su suplemento de originalidad; ésta, por ejemplo, muy similar a la del famoso Miró rasgado: el Miró de Cela, que cuando Miró confirma su falsedad a nuestro premio nóbel, éste lo rasga, pero Miró lo autentifica añadiéndole unas pinceladas y una firma ${ }^{33}$. Dicho sea entre paréntesis, Elmyr de Hory, cuando se le pregunta cuáles son sus artistas "favoritos", afirma de Miró: «Tampoco hice nunca nada de Miró. Me parecía tan fácil que nunca me atreví. Hasta los auténticos Miró parecen falsificaciones» ${ }^{34}$.

Pero nos estamos saliendo del tema. De todo esto, es suficiente con entender que las falsificaciones siempre están muy cerca del original, y en ningún caso lo eliminan. Por ello no hay que confundirlas nunca con las copias. Esto lo vio muy claramente Benjamin, cuando afirmaba que «cara a la reproducción manual, que normalmente es catalogada como falsificación, lo auténtico conserva su autoridad plena, mientras que no ocurre lo mismo cara a la reproducción técnica» ${ }^{35}$. Y, sin embargo, y aunque no confundamos copias y falsificaciones, el hecho es que ante esas ideas sobre las "falsificaciones originales" y las "máquinas de provocar acontecimientos", ideas que aparecen repetidas una y otra vez, no deja de resultar sospechoso un discurso sobre la cultura de la postproducción que pretenda pasar por modelo básico en las prácticas artísticas contemporáneas. Si de lo que se trataba era de provocar acontecimientos, a lo mejor no era necesario situar el conjunto en un discurso de duplicaciones y replicaciones. También la copia, claro, pero es sobre todo la falsificación la que provoca acontecimientos, y si toda falsificación remite, en el fondo a una "falsificación original" donde, con Benjamin, "lo auténtico conserva su autoridad", entonces es difícil desvincular la teoría de Bourriaud, con sus generadores de acontecimientos, de problemas similares. Y a ello habría que sumarle el hecho de que toda repetición -y aquí se están superponiendo la repetición de objetos o acontecimientos y la repetición de estrategias-, en nuestra cultura de masas no oculta su mayor miedo, esto es, que se la entienda como lo que es, como repetición. En los modelos seriales es la ley por excelencia: «la serialidad celebra siempre el placer de la repetición, pero invoca -sea de manera explícita o encubierta- el miedo al anquilosamiento, el anhelo terapéutico de regeneración» ${ }^{36}$.

32 C. Irving, ¡Fraude! La historia de Elmyr de Hory, el pintor más discutido de nuestro tiempo, tr. P. Posada, Madrid: Sedmay, 1975, p. 286.

$33 C f$. R. Gubern, Patologías de la imagen, Barcelona: Anagrama, 2004, p. 64 y ss.

34 C. Irving, op. cit., p. 290.

35 W. Benjamin, «La obra de arte en la época de su reproductibilidad técnica», loc. cit., p. 21.

36 J. Balló; X. Pérez, op. cit., p. 12. 
- El comunismo formal. Es la segunda conexión que quería establecer, aunque seré mucho más breve. Si la primera sitúa el nuevo discurso de la copia ante las múltiples dialécticas en torno a la falsificación, y, por tanto, aludiendo siempre a cierto suplemento de originalidad, ésta segunda nos coloca en relación directa con las metodologías de Guy Debord y la Internacional Situacionista. Es cierto que Bourriaud no oculta esta conexión entre sus postproducciones y los modelos situacionistas de desvío o tergiversación y práctica de la deriva, y, sin embargo, todo esto resulta extrañamente sospechoso. Me refiero, en general, a lo que Bourriaud llama comunismo de las formas: «Durante los años ochenta -escribe Bourriaud-, la democratización de la informática y la aparición del sampling permitieron el surgimiento de un paisaje cultural cuyas figuras emblemáticas son los DJs y los programadores. El remixador se ha vuelto más importante que el instrumentista, la fiesta rave más excitante que un recital. La supremacía de las culturas de la apropiación y del reprocesamiento de las formas introduce una moral: las obras pertenecen a todo el mundo, parafraseando a Philippe Thomas. El arte contemporáneo tiende a abolir la propiedad de las formas, en todo caso perturba sus antiguas jurisprudencias. ¿Nos dirigiríamos hacia una cultura que abandonaría el copyright en beneficio de una gestión del derecho de acceso a las obras, hacia una especie de esbozo del comunismo de las formas? $\gg^{37}$. Es importante destacar, y lo recuerdo una vez más, que nos encontramos analizando un modelo estratégico, un planteamiento general, y no obras o artistas determinados. Pero, de todos modos... i¿comunismo de las formas?!

En Debord y los situacionistas todo estaba lo suficientemente claro y respondía a una actividad crítica de intervención. Sobre el concepto de desvio, o tergiversación, dependiendo de las traducciones, es decir, la «reutilización en una nueva unidad de elementos artísticos preexistentes» ${ }^{38}$, escriben Debord y Wolman en ese texto casi fundacional de 1956 titulado «Métodos de tergiversación»: «Es por tanto necesario formar una representación paródica de lo serio donde la acumulación de elementos tergiversados, lejos de provocar y alentar la indignación o de hacer alusiones cómicas a las obras originales, expresará nuestra indiferencia hacia un original prohibido y sin sentido» ${ }^{39}$. Se trataba de negar todo, el pasado, el presente, el arte, la cultura... mediante un arma cultural que representara «la verdadera lucha de clases» al convertir toda herencia

37 N. Bourriaud, Post producción, op. cit., p. 39.

38 Internacional Situacionista, «El desvío como negación y como preludio», Internationale Situationniste, 3 (1959). Disponible en http://www.sindominio.net/ash/is0303.htm [Fecha de consulta: 20/VIII/2007].

39 G. Debord; G. J. Wolman, «Métodos de tergiversación», Les Levres Nues, 8 (1956). Disponible en http://serbal.pntic.mec.es/ cmunoz11/debord.html [Fecha de consulta: 10/ IX/2007]. 
literaria y artística en útiles para la propaganda de clase. En realidad, desvío es «abreviatura de la fórmula: desvío de elementos estéticos prefabricados» ${ }^{40}$, pero en ningún momento ha de confundirse con el collage, el montaje, etc., que, para los situacionistas, siguen siendo arte burgués. Es lo que les permite afirmar que, gracias a la facilidad y gratuidad de sus instrumentos, se llegará a una «educación artística proletaria, la primera etapa hacia un comunismo literario» ${ }^{41}$, donde toda la cultura anterior ha de tergiversarse... o eliminarse. Como dice Debord en La sociedad del espectáculo, toda esta teoría crítica «no es la negación del estilo, sino el estilo de la negación» ${ }^{42}$, por lo que, conectando con el tema del desvío y la copia, Debord realiza esa afirmación ya considerada clásica: «Las ideas se mejoran. El sentido de las palabras participa en ello. El plagio es necesario. El progreso lo implica. Da más precisión a la frase de un autor, se sirve de sus expresiones, elimina una idea falsa, la reemplaza por la idea justa» ${ }^{43}$.

Creo que es suficiente con esto. En resumen, la idea está lo suficientemente clara: en las estrategias situacionistas de intervención, el desvío y la copia actúan como modelos de antiideología, de negación de autoridad, de eliminación de originalidad, de supresión de pasados y presentes y, por supuesto, de desvalorización del arte. En el fondo, lo que estarían haciendo las prácticas artísticas contemporáneas es desviar el concepto de desvío, es decir, «manipular[r] los procedimientos situacionistas sin pretender la abolición del arte» ${ }^{44}$, con lo que se utilizan las obras preexistentes no para desvalorizarlas, sino para utilizarlas como un medio más: operaciones neutras, ajenas al valor crítico, y que únicamente buscan nuevos significados de objetos realizados, obras pasadas o acontecimientos sucedidos. Quizá, en el fondo, no sea más que nostalgia de postmodernidad.

Desvío del desvío, repetición de repeticiones, copia de metodologías que, a su vez, asumen la necesidad del plagio... y todo ello bajo la directriz conforme a la cual se elimina su parte más dura y crítica, con lo que no se recaería en los modelos situacionistas de intervención. Ante esto, yo, sinceramente, casi percibo mayor coherencia en los modelos situacionistas, que tienen lugar a finales de los cincuenta y durante todos los sesenta y, por tanto, plantean una conexión estricta con las necesidades epocales. Primero, no creo que pueda eliminarse fácilmente todo lo inherente a la parte crítica del desvío; segundo, toda

40 Internacional Situacionista, «Definiciones», Internationale Situationniste, 1 (1958). Disponible en http://www.sindominio.net/ash/is0108.htm [Fecha de consulta: 10/IX/2007].

41 G. Debord; G. J. Wolman, loc. cit.

42 G. Debord, La sociedad del espectáculo, § 204, tr. J. L. Pardo, Valencia: Pre-Textos, 1999, p. 166.

43 Ibid., § 207, p. 168. Traducción modificada.

44 N. Bourriaud, Post producción, op. cit., p. 42. 
repetición de metodologías muestra un olor a cadáver realmente desagradable; tercero, creer que se puede acudir a metodologías pasadas -que no son obras ni acontecimientos, sino estrategias, métodos $-\mathrm{y}$ volver a utilizarlas muestra un peligroso desconocimiento de la historia y, cuarto, todo esto no puede evitar situarse en la parte más inocente, más romanticona e inútil de los modelos actuales de intervención: si el modelo de la postproducción en su conjunto tiene como objetivo «romper la lógica del espectáculo», con lo que «el arte nos restituye el mundo en tanto que experiencia por vivir» ${ }^{45}$, creo que no han entendido muy bien a Debord y La sociedad del espectáculo, perfectamente situadas en su contexto epocal. Pero todo esto me lleva a la tercera conexión.

- La metáfora del bazar. Según Bourriaud, «podríamos representar el paso de los años ochenta a los años noventa yuxtaponiendo dos fotografías: la primera sería la vidriera de un negocio, la segunda mostraría un mercado de pulgas o una galería comercial en un aeropuerto. De Jeff Koons a Rirkrit Tiravanija, de Haim Steinbach a Jason Rhoades, un sistema formal ha sustituido a otro y el sistema visual dominante se acerca al mercado al aire libre, al bazar, a la feria, reunión temporaria y nómada de materiales precarios y productos de diversas procedencias. El reciclaje (un método) y la disposición caótica (esa estética) suplantan como matrices formales a la vidriera y los anaqueles» ${ }^{46}$. La metáfora de Bourriaud es coherente y muy expresiva: trata de mostrar el paso de la apropiación y la escultura de bienes de consumo a la postproducción, siendo los nombres de los artistas citados perfectamente indicativos. Para ello utiliza esa figura del bazar, del rastrillo o, a la francesa, "mercado de pulgas", donde las informaciones y las comunicaciones se mueven constantemente de un lugar a otro en un intercambio incesante de modelos culturales, que es lo que define a las estrategias de postproducción. Por supuesto, y desconozco sí Bourriaud es consciente de ello, esto conecta de inmediato con otra cultura, la del hacker y el software libre, y lo hace, precisamente, a través de la metáfora del bazar. Me refiero a que si Bourriaud tematiza esta metáfora del bazar como figura representativa de los nuevos modelos artísticos para distinguirlos de las prácticas apropiacionistas, algunos años antes, concretamente en 1998, Eric S. Raymond publicó un texto ya considerado clásico: su título era «La catedral y el bazar».

Lo que pretendía Eric S. Raymond en «La catedral y el bazar» era distinguir dos tipos de desarrollo de software completamente distinto, el software comercial y el software de dominio público, tipo Linux, basado, como se sabe, en lanzar versiones de prueba y delegar todo lo posible en la comunidad hacker. 
Si el primero se asemejaba al modo de construcción de las catedrales, silencioso, reverente y aislado, el segundo, la comunidad Linux, «parecía semejarse a un gran bazar bullicioso con diferentes agendas y enfoques (adecuadamente reflejado por los depósitos de software Linux, que admitían contribuciones de cualquiera) del cual sólo parecía posible que emergiera un sistema coherente y estable mediante una sucesión de milagros ${ }^{47}$. Que esos milagros se produjeron forma ya parte de la historia. Éste sí fue, y sigue siendo, un bazar coherente, un bazar que no jugaba con signos, sino con herramientas y versiones de prueba, un bazar serio que se enfrentaba a múltiples amenazas y lo hacía al perseguir unos objetivos lo suficientemente importantes: los derechos digitales, el software libre, el código de fuente abierta, etc. En ese bazar surgen los nuevos tecnohéroes, algunos ya clásicos como Richard Stallman, John Perry Barlow o el propio Eric S. Raymond, algunos más jóvenes, como el gran Linus Torvalds, y todos ellos, aquí sí, parten de una necesidad, la negación de la originalidad. Así, el propio Raymond afirma: «Ninguno de nosotros fue "original" en el sentido romántico que mucha gente asocia a un genio. Sin embargo, la mayor parte de la ciencia, la ingeniería o el desarrollo del software no es realizada por genios, aunque la mitología "hacker" mantenga lo contrario» ${ }^{48}$.

Ahora bien, ésta es la parte más interesante del modelo bazar, pero no camina sola. A su lado se encuentran todo tipo de modelos de intervención que, en mi opinión, representan innumerables paradojas. Es el problema básico del hacktivismo y el artivismo, el mismo en el que se cae cuando se pretende unir modelos situacionistas de contracultura con la espectacularidad de la red. Porque, si alguien lo dudaba, es en esa dialéctica en la que se basan tales modelos. En una parte importante de las estrategias de hacktivismo únicamente se consiguen dos cosas: o reforzar los sistemas de seguridad y control al hacer creer que su amenaza es para ser tenida en cuenta -con lo que «gracias a ello se disimula la alucinante desproporción del combate» ${ }^{49}-$, o mostrar la banalidad del hacktivismo crítico al basar sus estrategias en ingenuas, aunque espectaculares, intervenciones sobre páginas web ministeriales o de grandes multinacionales -las cuales, evidentemente, no tardan demasiado tiempo en limpiar su código-. Ésos son los dos únicos resultados conseguidos por cierto hacktivismo que, intencionadamente o no, ha caído en las redes del impacto mediático. Cuando ese hacktivismo se transforma en artivismo, en muchos

47 E. S. Raymond, «La catedral y el bazar» (1998), tr. J. Soto, disponible en http://www. sindominio.net/biblioweb/telematica/catedral.html [Fecha de consulta: 18/VIII/2007].

48 Ibid.

49 J. L. Brea, «El teatro de la resistencia electrónica (hackers, artistas y activistas)», en: J. L. Brea, La era postmedia. Acción comunicativa, prácticas (post)artísticas y dispositivos neomediales, Salamanca: CASA, 2002, p. 71. 
casos los resultados ni siquiera llegan hasta ahí, sino que se detienen en las bromas y un trasnochado sentido del humor que, en el fondo, muestra lo peor de la herencia situacionista.

La conclusión es obvia, y quizá no demasiado optimista: si la estrategia de postproducción mantiene su modelo de bazar, y, por tanto, es fácilmente asimilable con determinados elementos del activismo, entonces resulta muy problemático que el nuevo discurso de la copia mantenga su coherencia. Porque el resultado parece ser la colocación de tal discurso ante dos expectativas: o nos volvemos todos postmodernos, y así podemos seguir disfrutando hasta la extenuación de la multitud de simulacros y redes de signos, o nos convertimos en trasnochados situacionistas guiados por estrategias nostálgicas, románticas y, en el mejor de los casos, utópicas. Y digo el mejor de los casos... porque el peor es evidente: introducirse en la propia dialéctica del espectáculo. Ante estas dos posibilidades, quizá debamos mantener una postura más clásica, aunque se nos tache de conservadores. Ya hemos asumido los discursos de la copia en todas sus versiones: ¿estamos seguros que deseamos seguir forzándolos? Por supuesto, no los olvidamos y en ningún caso los pasamos por alto, pero quizá haya llegado un momento en el que, al igual que ha sucedido con la novela, después de todo tipo de citas, copias y postproducciones, y asumiendo su necesidad en un determinado momento, intentemos volver a la narración clásica. A la novela no le está yendo nada mal: la diferencia es que, en ella, no hay nostalgia de la postmodernidad, y no existe esa nostalgia porque a la postmodernidad se la asumió sin pervertirla. Quizá en el ámbito de las prácticas y teorías artísticas todavía no nos hayamos dado cuenta de que actualmente hay dos tareas fundamentales: en una coincidimos todos, revisar la historia del arte moderno; la otra nos cuesta más: asumir la postmodernidad, aceptar que un día fuimos postmodernos y aprovechar de ello todo tipo de enseñanzas, sin nostalgias... y sin desvaríos, el principal de los cuales sería repetir sus gestos.

$\mathrm{Y}$ concluyo. Un problema importante de las estrategias de la copia presentes en los modelos de postproducción consiste en creer que, una vez asimilado el objeto cultural, éste modifica su sentido y permite esos nuevos itinerarios de significado de los que habla Bourriaud. En el fondo, esto no es más que un romanticismo e idealismo levemente utópico, como lo era el de los situacionistas, aunque allí fuese coherente. No, no es tan fácil modificar significados: la realidad, la naturaleza, la cultura... no ceden fácilmente sus derechos. Sólo lo hacen si las idealizamos, si las ennoblecemos para poder pensarlas y, por tanto, convertirlas en fantasía. Pero la fantasía no puede asumir funciones que no le corresponden, como modificar la realidad. En este sentido, me gustaría concluir con un diálogo de la versión teatral de El gato con botas de Ludwig Tieck. La obra de Tieck es de 1797, y debe entenderse en el contexto crítico que algunos románticos hacían del idealismo -el propio Tieck, Friedrich Schlegel y sobre 
todo Jean Paul-, hecho que les mereció el odio eterno de Hegel.

Espero que se entienda la introducción de la cita de Tieck para concluir un discurso sobre la postproducción y la nueva cultura de la copia. Recuérdese que, según Bourriaud, el arte es un contrapoder que nos aporta contraimágenes, ya que «hoy existe una querella de las representaciones que enfrenta al arte con la imagen oficial de la realidad $»^{50}$. Si es así, y a fin de aportar mi granito de arena, me permito concluir con un texto que también habla de la realidad:

Rey [...] iAy qué dolor, el árbol está lleno de orugas!

PRINCESA Es que se trata de una naturaleza todavía sin idealizar; primero ha de ennoblecerla la fantasía.

Rey Ahora desearía que tú, con tu fantasía, me pudieras librar de las orugas $^{51}$.

50 N. Bourriaud, Post producción, op. cit, p. 122.

51 Ch. Perrault; L. Tieck, El gato con botas, tr. M. Sarabia, pról. F. Duque, ilustr. C. Bloch y M. Galanda, Madrid: Abada, 2003, p. 104. 